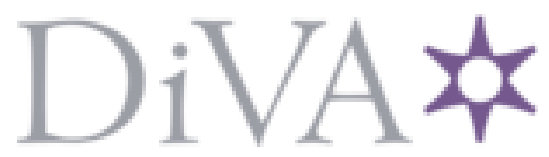

http://www.diva-portal.org

\title{
Postprint
}

This is the accepted version of a paper published in Intensive \& Critical Care Nursing. This paper has been peer-reviewed but does not include the final publisher proof-corrections or journal pagination.

Citation for the original published paper (version of record):

Haraldsson, L., Christensson, L., Conlon, L., Henricson, M. (2015)

The experiences of ICU patients during follow-up sessions: A qualitative study.

Intensive \& Critical Care Nursing, 31(4): 223-231

http://dx.doi.org/10.1016/j.iccn.2015.01.002

Access to the published version may require subscription.

N.B. When citing this work, cite the original published paper.

Permanent link to this version:

http://urn.kb.se/resolve?urn=urn:nbn:se:hj:diva-26398 


\section{THE EXPERIENCES OF ICU PATIENTS DURING FOLLOW-UP SESSIONS - A QUALITATIVE STUDY}

Lena Haraldsson, RN, CCRN, $\mathrm{MScN}^{1}$

Lennart Christensson, RN, CCRN, PhD, Associate Professor ${ }^{1}$

Lisa Conlon, RN, DNurs ${ }^{1}$

Maria Henricson, RN, CCRN, $\mathrm{PhD}^{1}$

${ }^{1}$ School of Health Sciences, Jönköping University, Box 1026, SE-551 11 Jönköping, Sweden

Email: Lena.Haraldsson@hhj.hj.se Phone: +46 361012 48, Fax: +46 36101250

Email: Lennart.Christensson@hhj.hj.se Phone: +46 361012 49, Fax: +46 36101250

Email: Maria.Henricson@hhj.hj.se Phone: +46 361012 52, Fax: +46 36101250

The manuscript has a total of 5174 words

Key Words: content analysis, follow-up, intensive care, memories

Conflict of interest

The authors have no conflict of interest.

Funding/Sponsorship

This research was supported by grants from the Local Research and Development Council, Jönköping County, Sweden. 


\begin{abstract}
Objective: Evidence supports the recommendation for follow-up session(s) for patients after discharge from an intensive care unit (ICU). The aim of these follow-up sessions is to allow patients to express and discuss their experiences and problems following their time in an ICU. To optimize the knowledge gained from the follow-up session experience, it is necessary to describe how patients experience these sessions. The aim of this study was to describe how ICU-patients, experience a follow-up session.
\end{abstract}

Design/setting: This study adopted a qualitative design utilizing semi-structured interviews, and which examined the experiences of seven men and five women. Qualitative content analysis was utilized.

Findings: The participants stated that the information gained from these sessions, which had previously seemed unclear to some of them, was, on the whole, now clarified and confirmed. A discernible difference was found between participants who were cared for at general ward and those who were cared for at a rehabilitation ward and also were offered a meeting with a counselor, following discharge their from the ICU. The findings also indicated that participants who were not offered psychosocial support showed a greater need for a follow-up session.

Conclusion: This study has highlighted the need for increasing collaboration between intensive care staff and staff in other units to provide support to this patient group in order to reduce their suffering post intensive care experience. 


\section{Introduction}

The use of follow-up sessions are commonly used both in Sweden and internationally for patients who have previously been cared for in an Intensive Care Unit (ICU). The overall aim of these follow-up sessions is to allow patients and their relatives the opportunity to express their experiences and problems, and if needed to refer these individuals to other healthcare professionals (Egerod et al.,2013; Pattison et al., 2007; Samuelson and Corrigan, 2009). These follow-up sessions, commonly consist of three steps. Firstly, a diary is kept by staff and relatives, detailing the patient's time in the ICU. The next step involves a member of the ICU staff visiting the patient on the ward they have been transferred to. This usually occurs a few of days after discharge from the ICU. Finally, a consultation session is organized approximately two months after discharge from the ICU (Egerod and Christensen, 2009; Engström et al., 2008; Samuelson and Corrigan, 2009). Follow up sessions are offered to patients after their discharge from the ICU, and have been shown to have a positive effect on the individuals rehabilitation and recovery (Samuelson and Corrigan, 2009). It has also been shown that this, among other things, give these patients a better understanding of what they have gone through as well as the opportunity to put this knowledge into words. This has been shown to give these individuals the opportunity to make sense of their experiences, and it is hoped that this will assist the patient to move on from this experience (Chaboyer and Grace, 2003; Samuelson and Corrigan, 2009; Strahan et al., 2003). Samuelson and Corrigan (2009) show that patients, as well as their relatives, appreciate these follow-up sessions, with this shown to assist some patients and relatives to move on from their ICU experience. Factors that have been shown cause to patients stress during their time in the ICU, such as; being thirsty, wearing a continuous positive airway pressure (CPAP) mask, not being able to communicate and being moved to another care unit, have been identified (Samuelsson and Corrigan, 2009). 
In the Backman et al. (2010) study, patients who have been allowed to read the diary written for them were shown to experience a higher quality of life at follow-up. The patient diaries show what occurred to the patient, and may be a way in which to fill memory gaps, to explain certain memories (Engström et al., 2008), and can offer the ICU staff a new insight as to how future care should be designed (Egerod and Christensen, 2009). Photographs are also taken (with the permission of the patient or next of kin), and put in to the diary (Backman et al., 2010; Backman and Walther, 2001; Jones et al., 2010). Backman and Walther (2001) have shown that the use of photographs is appreciated by many patients. Patients who have been cared for in an ICU also expressed that a diary helped them gain an insight into the experience. Contrary to this benefit, the reading of a diary has also been shown to be experienced by some as painful or unpleasant (Engström et al., 2008).

Research has also shown that patients' experiences can consist of both pleasant and unpleasant memories of their time in the ICU, with some patients describing their experiences as; dreams, nightmares, fantasies and perspective changes with frightening delusions (Roberts et al., 2006; Samuelson, 2011). Ringdal et al. (2006) state that four out of five patients who have had physical trauma have some memories from the actual events during their time in care, and the remaining one out of five, have experiences of false or unreal memories. Examples of these false or unreal memories include: illusions of people trying to injure them (Löf et al., 2006). It has been shown that memories of time spent in an ICU can change over time, but the emotional effects on patients, such as anxiety, appear to remain (Löf et al., 2006; Rattray et al., 2010). Therefore, the use of follow-up sessions may assist with dispelling some of these unpleasant memories, and/or reinforcing some of the more pleasant memories patients may have. 
ICU patients are commonly offered an opportunity to attend a follow-up session before they are discharged from hospital (Egerod et al., 2013). ICU staff visit the patient following discharge from the ICU to provide both verbal and written information about the proposed follow-up session (Egerod et al., 2013; Samuelsson and Corrigan, 2009). These follow-up sessions offer an opportunity to give realistic and honest information that can assist in attempting to explain the patient's experiences. In addition to this, follow-up sessions can provide an opportunity to ask if the participants require support in promoting their wellbeing and/or increasing their quality of life (Nåden and Eriksson, 2002; Samuelson and Corrigan, 2009). There is clear evidence that follow-up sessions have many benefits for the patient, as well as their relatives, and staff who provide care to these patients (Cutler et al., 2003; Rattray et al., 2010; Samuelson and Corrigan, 2009). With the aim of improving care for future intensive care patients, the nurses responsible for these follow-up sessions should provide their colleagues feedback based on what has been highlighted and observed in the follow-up sessions (Cutler et al., 2003; Egerod et al., 2013; Samuelson and Corrigan, 2009).

Information regarding the patient's time spent in the ICU is often requested by patients and their next of kin. It is intended that as much information as possible is provided during the follow-up sessions. It is hoped that this information will clarify and address any questions relating to the patients particular memories, nightmares, and any remaining difficulties from their time spent in the ICU. This can also serve as a valuable knowledge tool for ICU staff (Samuelson and Corrigan, 2009; Storli and Lind, 2009). Therefore, the aim of the study was to describe how ICU patients, experience a follow-up session.

\section{Method}

\section{Design}


This study utilized an explorative and descriptive design based on qualitative content analysis with an inductive approach. The semi-structured interviews focused on patients experiences of a follow-up session following their intensive care experience.

\section{Sample and settings}

Participants were recruited from a district hospital in Sweden. The study setting was a four-bed general ICU that receives both surgical and medical admissions. In total 60 nurses and assistant nurses are employed in this ICU. At the time of the study, the patient per staff ratio was about two patients for one Registered nurse $(\mathrm{RN})$ and one assistant nurse. One nursing staff member is the most time present in the ICU room. The follow-up sessions consist of three steps. A diary is written by the nursing staff and/or the patients relatives. The nursing staffs begin writing the diary as soon as possible, often at day two of admission. The ICU staffs give the diary to the patient when they were discharged from the ICU. Following this, a member of the ICU staff visited the patient on the ward they had been transferred to. This usually occurred a number of days after discharge from the ICU. Approximately six weeks following discharge from the ICU, a member of the ICU staff contacted the patient and offered them an opportunity to attend a follow-up session. Finally, a follow-up session was organized approximately two months after discharge from the ICU. Prior to the commencement of the follow-up session, the patient, their relative(s) and/or caregiver(s) are met by a $\mathrm{RN}$ and an assistant nurse or two RNs. For the purpose of this study, the term `relative' will refer to; a husband, wife, live-in career, child, next of kin, or a close family member. One hour was allocated for each follow-up session, which included a conversation and a visit to the ICU. However, should more time have been needed, additional time was made available. The follow-up sessions for this study were conducted in a private room behind the ICU. During the session, the participants also had the opportunity to 
go back to an ICU room to see where they have been cared. Some patients were also offered the opportunity to speak to a counselor, after the follow-up session, if needed.

Eligible sampling was used for this study (Polit and Beck, 2012). The first author (LH) informed the ICU staff about the study based on the study's aim and inclusion criteria. The inclusion criterion were that the participant needed to be: a Swedish speaker, $>18$ years of age, who had been admitted to the ICU for more than 96 hours (as recommended by the Swedish Intensive Care Register [SIR 2013]), and had returned to the ICU for a follow-up session approximately two months after discharge. Patients with dementia, a diagnosis of a psychological condition or cognitive disabilities before being cared for at the ICU, were excluded from the study. On initial examination, 13 patients were found to be eligible for inclusion in the study. However, one participant was later excluded due to the identification of a cognitive disability. It was found that this individual's level of understanding in regards to his ability to consent to participate in the study could not be appropriately ascertained. The remaining 12 patients received information about the study from the nurses during the follow-up session. A few days after the follow-up session, the first author ( $\mathrm{LH})$ contacted the patients and made an appointment for an interview. All 12 patients gave their informed consent. Of this 12, seven men (to be known as Male A, B, C, D, G, H, I) and five women (Female E, F, J, K, L), with a mean age of 54 years, were interviewed. These interviews occurred two to twelve days after the patient's follow-up visit to the ICU. The main interview question posed was: "Could you please tell me about your experience of the follow-up session to the ICU?" Additional questions, for example; "What do you mean? and/or Could you tell me more?" were also asked for clarification and to elicit more detailed information. All of the interviews were conducted by the first author in a quiet place and at a time specified by the participants. Of the 12 participants, eight interviews took place in the participant's home, with the remaining four, in a room at the hospital. The interviews were 
audio-recorded, and lasted from 16-40 minutes. The participants were also asked to bring their diary to the follow-up session, if they had one. All interviews were transcribed verbatim. Data collection took place between December 2007 and September 2008. During a year, approximately 25-30 patients attend a follow-up session. It was envisaged that the researchers would have the opportunity to include 20 patients in the study. However, after a 10 month period only 12 participants were involved in the study. The researchers decided to end the data collection.

\section{Data analysis}

Data analysis was conducted according to Graneheim and Lundman's (2004) content analysis. Content analysis is a method of analyzing written or verbal communication in a systematic way (Krippendorff, 2004). This method was deemed appropriate for this study as the aim was to attain a comprehensive and broad description of the phenomenon and focus on the differences and similarities within the text (Graneheim \& Lundman, 2004). The analysis was inductive and focused on the manifest content, which can be described as an analysis of the visible and obvious components in the text (Downe-Wamboldt, 1992). The analysis was performed in several steps. To become familiar with, and understand the content of the material in the context, the recordings were listened to in their entirety, and transcripts were read repeatedly by the first author. Initially, three domains were identified: Consultation with nursing staff; Visit to ICU and The use of a diary. After discussion with LC and MH (coauthors), sentences and phrases with information relevant to the aim of the study were identified and sorted into meaning units (654 in totals). To reduce the text, each meaning unit was condensed to reduce the amount of the text while maintaining the core. The condensed text was then sorted, abstracted and labeled with a code. Similar codes were assembled into preliminary subcategories (Table 1). It is important to note that the subcategories reflect the 
core message of the interviews. The main author then met the co-authors (LC and MH) again and after discussion, adjustments were made and a final list with two main categories "Filling a memory gap with information" (with three subcategories) and "The ability to move on" (with two subcategories) was created (Table 2). To ensure the main categories and subcategories were trustworthy, the analytical process involved a back and forth movement between the whole text and its parts. For example, each meaning unit and coded section was cut out and pasted within the appropriate subcategory and category to validate the analysis.

\section{Ethical considerations}

Ethical approval was gained from the clinic's director at the hospital. According to Swedish law (VRFS 2012:1), which deals with vetting the ethics of research that involves humans, research on the deceased, biological material from people and research that involves dealing with sensitive information about people or personal information concerning offences against the law was adhered to. The participants were informed about the aim of the study by letter and also verbally prior to gaining consent and the commencement of the interviews. Participants were assured of the voluntary nature of their participation with all 12 participants giving their written informed consent. Confidentiality was assured by the coding of data, with all data were stored on a password-protected computer. This was explained to all participants prior to gaining their consent (Human and Fluss, 2002).

\section{Methodological discussion/limitations of the study}

The most obvious limitation for this study was the sample size and the age of the data. Data collection took place between December 2007 and September 2008. During a year, approximately 25-30 patients attend a follow-up session. The aim of the research was to include at least 20 patients in the study. Only 12 participants agreed to take part in the study in 
the first 10 months, therefore the researcher felt it was appropriate end the data collection at this stage. However, the interviews conducted resulted in a large amount of material, illuminating differences and similarities in the participant's experiences of follow-up sessions. Therefore, 12 participants were assessed to be enough, as trustworthiness in a qualitative study was gained more by the richness of each interview, than by sample size (Sandelowski, 1995). Although research being conducted at only one site may be seen as a limitation, the rich data collected and the knowledge gained from this one site provided new knowledge as to the advantages of conducting follow-up sessions for post ICU patients. This knowledge will assist other healthcare units to provide holistic care to their patients. It has been observed that few things have changed over the years at this ICU. As a result of the present study, the staff now offer follow-up sessions to patients with disabilities who are unable to visit the ICU (this is undertaken by visiting the individuals) and is also offered to patients a second and optionally a third follow-up session, if needed. Our impression, however, is that the experiences of the participants in this study could be transferable to patients at a general ICU with four to eight beds, and with a patient per staff ratio about two patients / two nurses. Transferability (Lincoln and Guba, 1985) of the findings is, for that reason, possible.

In regards to establishing the studies credibility (Lincoln and Guba, 1985), the researchers dealt with their pre-conceived knowledge and ideas (all four researchers are ICU nurses, but not currently working in the clinical environment), by documenting this information, attending peer debriefing and communicating with colleagues and researchers with no experience in caring for patients in an ICU. The selection of participants also strengthened the study; partly because they were chosen by the staff working in the ICU, and not by the researchers, and partly because the participants reflect a diversity of age and gender. The first author (LH) was an ICU nurse at the unit in the study at the time of data collection, but did not meet with the participants in connection with the follow-up sessions. One participant 
expressed that he remembered his interviewer from his time in ICU. This could be considered as both a strength and a weakness of the credibility (Frank et al., 2011). On the one hand it is strength, as it could make the patient feel safe in the interview situation, on the other hand it is a weakness as the interviewer could be perceived as having the power and the patient may have feel inferior. The analysis was continuously discussed with co-authors during all phases, such as coding and grouping of codes to ensure trustworthiness (Graneheim \& Lundman, 2004). In regards to future similar research into this topic, underpinning others research may assist with analysis of future data. Finally, this small ICU, with only four beds and about 60 nurses in the staff, could have affected the patient's perception of the follow up session, and weakened the trustworthiness of the findings. This was not found to be the case in this study. All 12 patients stayed four days or more and met, with high probability, all the staff. In addition, six patients had spent time at an ICU in a university hospital and maybe have memories from that ICU also.

\section{Findings}

The analysis of the data identified three domains and two categories. The domains were: "Consultation with nursing staff", "Visit to the ICU” and "The use of a diary". The categories were: "Filling a memory gap with information" and "The ability to move on". The main category "Filling a memory gap with information" resulted in three subcategories: "Confidence in experiences", "A wish to understand and know more" and "Follow-up in welcoming environment". The main category; "The ability to move on" was further broken down into two subcategories; "The importance of reunion" and "Confirming their experiences with the use of a diary" (Table 2). It was found that the participants felt that it was meaningful to them to be able to return to the ICU for a follow-up session following discharge from the 
unit, as many of the participants had unclear memories of what they had experienced. These memories were often given meaning after the patient's discussions with the ICU staff.

Furthermore, the follow-up sessions acted as a method for processing this gained information for the participants in regards to the time spent during their time in the ICU. This was found to be beneficial to the participants in order for them to be able to move on from this experience. A variation was identified in the experiences of the participants. It was found that there was a tendency for those who had been transferred to a rehabilitation ward after discharge from the ICU, did not require the same need for a follow-up session, compared to those who had been cared for at a surgical or medical ward. The study also showed that those participants not offered a chance to meet with a counselor, experienced a greater need for a follow-up session.

Table1. Example of analysis process

\begin{tabular}{|l|l|l|l|}
\hline Meaning unit & Condensed & Code given & Subcategory \\
'It's like this, when you & When you don't & Want to know & A wish to \\
don't remember anything & remember...it's & understand and \\
to hear about it & nice to hear about & & know more \\
afterwards'. (Male B) & it & The importance \\
\hline $\begin{array}{l}\text { 'And I got to meet with } \\
\text { one of the nurses who }\end{array}$ & I was able to meet & Meeting with & of reunion \\
had taken care of me too. & nurses who had & positive & \\
And...that they...I guess & taken care of me & & \\
that's what's positive'. & & &
\end{tabular}




\begin{tabular}{|l|l|l|l|}
\hline $\begin{array}{l}\text { 'Otherwise you go } \\
\text { around wondering what }\end{array}$ & $\begin{array}{l}\text { You wonder about } \\
\text { what was done so }\end{array}$ & A diary is valuable & Confirming \\
they've done to you and & the diary was a & their \\
so the diary was good & good thing to & experiences \\
because there you can & follow & with the use of \\
follow it day by day'. & & a diary \\
(Female J) & & & \\
\hline
\end{tabular}

Table 2. Overview of results with domains, subcategories and categories

\begin{tabular}{|l|l|l|}
\hline Domain & Subcategory & Category \\
\hline Consultation with nursing & Confidence in experiences & Fill a memory gap with \\
information & $\begin{array}{l}\text { A wish to understand and } \\
\text { know more }\end{array}$ & \\
\cline { 2 - 2 } & $\begin{array}{l}\text { Follow-up in a welcoming } \\
\text { environment }\end{array}$ & \\
\hline Visit to ICU & The importance of reunion & The ability to move on \\
\hline The use of a diary & $\begin{array}{l}\text { Confirming their } \\
\text { experiences with the use of a } \\
\text { diary }\end{array}$ & \\
\hline
\end{tabular}

\section{Filling a memory gap with information}

Following analysis of the data, the category 'Filling a memory gap with information' was identified. This category further resulted in the following subcategories; 'Confidence in experiences', 'A wish to understand and know more', and 'Follow-up sessions in a welcoming environment'. Taking part in the follow-up sessions was found to give the participants an insight into what had actually happened to them during their time in the ICU. Participants stated that the information gained from this follow-up session, which, for some, 
had previously seemed unclear, was now clarified and confirmed. This was one of the major findings of the study.

\section{$\underline{\text { Confidence in experiences }}$}

In regards to the confidence in experiences of the participants, a lack of knowledge and a feeling of not knowing what they had experienced led to a feelings of growing concern for some of the participants. Some participants believed that a follow-up session provided an opportunity to learn that many of the things they were experiencing, for example: that the rehabilitation process, can take a long time, and that this was not something to be concerned about. Being able to return to the ICU environment, ask questions and have the opportunity to process one's difficult experiences, was also seen as positive for some of the participants, and was said to often gave them strength. Participants who, after discharge from the ICU, and who had been cared for at rehabilitation ward, and who had contact with a counselor, stated that the times spent with a counselor was beneficial. These participants also stated that counseling session provided them with the opportunity to process the time spent in the ICU, more easily.

"If I hadn't gotten that help [from the counselor], it would've felt meaningful to ask questions and straighten things out [at the follow-up session] because anyway it happens that what you remember can be twisted or right, which can be nice to get confirmed." (Female E)

Other participants, who had not been cared for at a rehabilitation ward, or had not had contact with a counselor, expressed that the follow-up sessions were in fact the first time they had been able to talk about their experiences with a healthcare professional. For these individuals, this opportunity gave them a feeling of security.

"Yeah, I think so. That security you get from being able to meet with them [healthcare professional] and such, feels good to me." (Female J) 
Participants also stated that they felt strengthened by the chance to attend a follow-up session, as they were able to have some of the events they had experienced confirmed and explained. They also said that the sessions allowed them an opportunity to move on in processing and understanding their experiences, and not to worry about things that were unclear. Some participants stated that the follow-up session was a way in which to possibility to avoid depression experienced by many people who had been an ICU-patient.

"They [ICU-patients] can be very depressed for a long time ... they need this support to provide a perspective..." (Male G)

\section{$\underline{\text { A wish to understand and know more }}$}

At the follow-up sessions, the ICU staff attempted to answer all of the questions asked by the participants regarding their time in the ICU. Details were provided and were directed specifically to the individual. This said, some participants stated that they did not receive any new information from the follow-up session, but they had their thoughts and memories confirmed and in which gave more insight. These participants said that they had received information from their next of kin and expressed no need for more information. However, the study identified that a feeling of exclusion could arise as it was difficult to accept that one's next of kin knew what had happened, when an individual was not aware of it oneself.

“I really don't know much about it [the time in ICU], because I was so sick you ..., so...I don't really know what I was doing." (Male H)

Gaps in memory and the lack of time perception also contributed to some of the participants having difficulty remembering the course of events while in the ICU. Some felt that each day was like any other. Participants expressed their desire to understand and know more. 
The study highlighted that the use of photographs in the diary showed how the environment had looked and also how the participants had looked during their time in the ICU. This was found, by some participants, to be helpful.

\section{$\underline{\text { Follow-up in a welcoming environment }}$}

Some participants stated that they felt nervous and tense prior to returning to the ICU for the follow-up session. They stated that much of this tension subsided, when the staff met them and invited them into a welcoming environment. Some participants stated that they felt they could influence the meeting in a positive manner. The follow-up sessions were conducted in a private room behind the ICU. Some of the participants stated that the room they were in was a calm and pleasant place in which to talk. They felt that this made it easier to establish a better rapport with the ICU staff. Participants also stated that it was nice to be able to talk in a different room from the ICU, as for some of the participants, this was associated with unpleasant memories and feelings. Being able to express themselves, in regards to what to talk about and what questions to ask the healthcare staff, was seen to be a positive experience for some of the participants. The ICU staff conducting the follow-up sessions, were seen as experienced, skilled and accommodating, with some participants appreciating being asked about their ICU experience.

“...I think you took the time, and that I had the chance to ask questions ... I could choose myself if I wanted to ask questions or not." (Female L)

Others stated that the staff expected them to talk about their experiences at the follow-up sessions, but that they did not expect anything from the staff in return. Some participants stated that they would not normally have contacted the ICU staff themselves to request a follow-up appointment, but felt it was nice to be invited to attend a session.

\footnotetext{
“..I probably, would not have contacted them myself...” (Female L)
} 


\section{The ability to move on}

The follow-up session experience was seen by some of the participants as helpful with the participant's ability to move on with their life following their time in the ICU. The subcategories identified from this category were; 'The importance of reunion' and 'Confirming their experiences with the use of a diary'.

\section{The importance of reunion}

The follow-up sessions entailed returning to the ICU and visiting a patient's room in the department. When it was time to return to these areas, some participants stated that they experienced a feeling of tension, with some unpleasant memories and feelings, but none of the participants wished to refrain from returning to the ICU.

"And you think, oh now I'm going to be in that environment where I was in such bad shape. But...I didn't experience it like that when I got there." (Female L)

The time spent in the ICU waiting room before the follow-up session commenced, was also said to cause unpleasant feelings by some of the participants. For some of the participants this area was associated with their next of kin having spent a great deal of time in this room while the participant was in this acute environment. On returning to the ICU, participants who had had contact with a counselor following their discharge from the ICU, realized that they had already developed coping strategies prior to the follow-up session, but stated that this session was another way to help them move on with their lives. For some participants, seeing the room they had been cared for in the ICU also caused mixed feelings.

'So it wasn't some kind of reunion now, either happy or sad in any way, it was rather just to say here's where you were before..." (Male I) 
The ICU nursing staff also showed the participants the equipment used when caring for an ICU patient. This resulted in one participant stating that this was difficult because it reminded her of how seriously ill she had been, and this brought back bad memories. Other participants stated that they thought it was interesting to see the ICU equipment. If a participant had no memories at all from their time in ICU, seeing the room they had been cared for, provided no additional information to help fill their memory gaps. Some participants stated that they appreciated being asked to return to the ICU, and some expressed gratitude to the staff for not having forgotten them. Some of the participants also stated that it was valuable to return to the ICU. For these participants it was a way in which they felt alive and healthy again. For some, it was an emotional time with some saying that they had shed tears of joy when they returned to the ICU.

\section{Confirming their experiences with the use of a diary}

For some of the participants the use of the diary provided a way in which to explain their time in the ICU. The diary that most participants had had written for them was appreciated and was said to be often read carefully by them. The diary provided information and an understanding about their time in the ICU. The use of a diary was also seen to be beneficial to read by the participant, and had allowed these individuals to become aware of what had occurred day by day during their time in the ICU. If a participant had not been given their diary at discharge, some said that they would not have had an insight into what they had gone through, since "everything's in there"

“...if you read something in a diary, that's also something you get your own ideas about ...so it's very, very good." (Female E)

Reading the diary was also described as emotional, with some participants stating that they cried every time they read it. 
"I have cried every time I have opened it. It has been too much" (Female K)

Others stated that the diary did not offer much, and they did not read it in depth or use it as a reference. One participant did not have a diary written for her, as no one had made notes during her time in care. This participant stated that the follow-up session did not provide as much new information as it might have if there had been a diary that they could refer to. Some participants also said that there were gaps in the diary between the time in the ICU, and following discharge from the ICU. This made it difficult for some participants. Furthermore, some of the participants had a desire for their relatives and/or staff to continue writing the diary following their discharge from the ICU and prior to being discharged from hospital or the rehabilitation ward. These participants said that they wanted the diary to be maintained until they could write in the diary themselves. Some participants, who were cared for at a rehabilitation ward following discharge from the ICU, described how their next of kin had also maintained a private diary for them, which they appreciated. The findings of this study has also highlighted the benefits of follow-up sessions and the positive aspects experienced by some of the participants.

\section{Discussion}

The main finding, "Filling a memory gap with information", was seen as providing participants with clarification and confirmation about their memories. Patients cared for at a rehabilitation ward following discharge from the ICU, stated that they had often processed their experiences through visits with a counselor, psychologist and/or consultation team. These participants stated that they did not have the same need for a follow-up session as other patients did. Those who did not have contact with a counselor expressed that they felt that they had more of a need for a follow-up session, and had, therefore, valued it higher. Jones 
and Lyons (2003) also showed that many ICU patients have psychological problems and a greater need for contact with a counselor or psychologist after being cared for at an ICU.

The participants' experiences varied in regards to their need for a follow-up session. This knowledge should be provided to healthcare personal in order to enhance the efforts at the ICU and/or with outpatients departments for faster psychological and physical assessment and rehabilitation. Increased cooperation between staff in the ICU and the post ICU care units, focusing on early planning for a patient's transfer and an increase in rehabilitation support, is just one way to achieve this (Lin et al., 2009). Today in this ICU involved in this study and many other ICU departments, staff from other departments caring for discharged ICU patients only meet briefly to discuss and handover the patient. This is often the only opportunity to gain information about the patients time in ICU. This study and other research has found this approach to not be optimal (Forsberg et al. 2011; Lin et al. 2009). Staff in the ICU, as well as those in the post ICU care units, need to have knowledge and an understanding about the patient's experience of their time spent in hospital. This knowledge would be valuable in attempting to identify a patient's crisis reaction at an early stage and offer support. This would also assist in allowing a patient to express a need for other forms of assistance (e.g. counselor or psychologist) they may require. Staff should also be trained to meet the information needs of their patients and the patients next of kin when transferring the patient to a ward (Paul et al., 2004). Some participants stated that their transfer to a care unit, following discharge from the ICU, caused feelings of insecurity, anxiety and vulnerability. These feelings need to be appropriately addressed by staff as soon as possible. Forsberg et al. (2011) highlights that it is important for patients to know what is going to happen after their time in the ICU. It has also been observed that some patients can experience the ICU environment as stressful, and then find the post ICU care unit peaceful (Forsberg et al., 2011). 
The use of a diary was also found to be of great benefit to some of the participants. Some participants of this study also expressed a desire for the continued writing in their diary at the post ICU care units. Images of reality available through the use of photos in the diary, as well as visiting the ICU during the follow-up session, gave many of the participants greater insight into their time spent in the ICU and provided support in processing what had occurred during this time. Previous studies (Backman and Walther, 2001; Knowles and Tarrier, 2009) show that a personal diary containing photos and a detailed account of the patient's experiences of their time in ICU is valuable to many. Diaries were also reported to be a useful tool in processing information after being in an ICU, and were found to cause less anxiety and depression for these patients. Descriptions of what has happened during a patient's time in ICU can be viewed as emotionally difficult, but also as positive to some of these patients. This is evidenced when patients state that they have learned of the care their next of kin provided for them during the patient's time to ICU, for instance, the keeping of a diary. A desire was also expressed by some of the participants for additional information (sub-category "A wish to understand more") upon discharge and more support from post ICU care unit staff after discharge from the ICU.

As a result of this study, the following recommendations are made to address concerns and issues raised by the participants. A rehabilitation program including a manual for the patient addressing the rehabilitation process may be effective in helping regain one's physical function and reducing depression. Jones et al. (2003) provides details of such a manual, with Salisbury et al. (2010) also describing a model in which a rehabilitation assistant can support the patient in their rehabilitation journey at the post ICU care unit. This model and the details contained in this model would also assist staff to provide appropriate support to these patients while in these units. Prinjha et al. (2009) also shows that ICU patients appreciate participating in follow-up programs. However, some participants also stated that their health 
needs are not met by the follow-up session, as the hospital was not able to fulfill their needs. These individuals believe this is due to the fact that hospitals were unable to provide the aftercare they required (Prinja et al., 2009).

Some participants also stated that they felt strengthened in having gone through the ordeal of having been an ICU patient. Barnett (2006) asserts that this patient group - having been near death - is often neglected, and refers to "the mayday psychological aftercare service" (p. 5), a support program created by a psychologist for patients who have been in an ICU. The focus of the program is to offer support for the patient's need for understanding and the ability to find meaning in their experience of having been close to death. Nursing staff need to build a rapport with their patients and become close to them. These nurses need to listen to their patients stories about their memories and/or the lack thereof, and be able to alleviate any suffering this might have caused (Nåden and Eriksson, 2002). The time at, and after, an admission to the ICU, can cause patients suffering from both their illness (due to trauma, illness and/or surgery), and from the care they have received in the ICU, with these issues needing to be addressed. Although suffering cannot be completely eliminated, it is considered possible to reduce this suffering through love (as identified in Eriksson's theory about suffering) and make this suffering more bearable during the progression of this situation (Rehnsfelt and Eriksson, 2004). The use of follow-up sessions allows many patients to face the suffering they have endured and become more aware of the reality they have gone through in order to process this information themselves. However, the participants of this study had varying opportunities to do this, with some expressing a desire to understand and know more.

Emotional reactions and expressions of experiencing the follow-up sessions as a step in processing what one has been through reflects the importance of offering patients help. It also assists in the possibility of understanding their experiences in the ICU for themselves. According to Williams (2009), various fragments in a patient's memory can help with the 
psychological recovery process. The findings of this study show the importance for an individual who has been in ICU to understand and know more about what had happened during their time in ICU. The study has also shown that being a patient in ICU impacts on the patients future life, and with the help of a follow-up session, these individuals can find meaning in their life, existentially or ontologically (Storli et al., 2008). The findings also highlight the experiences of emotional difficulty by some, for example, nervousness and insecurity involved with returning to the ICU. Storli and Lind (2009) support this, and assert that a return visit to the intensive care room in which they were cared for, can cause feelings of gratitude about having survived this event, and assist with things falling into place. This visit can also make the experience more meaningful through the verbalization of one's feelings and the expression of wanting to face the emotionally difficult aspects at one's own pace. This journey for a search for meaning shows the need for the follow-up of ICU patients, as well as the opportunity and subsequent support in allowing these individuals to discuss their experiences (Storli et al., 2008). Experiences of happiness, gratitude and the ability to move on were highlighted in the results. There was also a desire, by some of the participants to understand one's experiences from the time spent in intensive care (Engström et al., 2008). This study has highlighted the fact that further research is needed to assist with identifying what ICU staff can do to the facilitate a smooth and uneventful discharge for their patients. It is hoped that this knowledge will assist ICU staff and post ICU care unit staff to provide the most appropriate support to these specific patients. The use of follow-up sessions has been shown to be a valuable way in which to provide a holistic approach to these patients, but requires continual education to staff to ensure suitable support is available to all ICU patients. Research and continued development of appropriate post care models will also be valuable to provide staff with ways in which to provide the best care to these patients. These models will 
also greatly assist the patient to feel empowered in their recovery from this, for many, traumatic event.

\section{Conclusion}

This study has highlighted that patients who have been cared for in an ICU and who had attended a follow-up session, experienced these sessions as a valuable tool in the processing of their feelings and emotions. It was also seen that these session provided some participants with the tools to move on from their experiences of being a patient in an ICU. The study also identified that those patients who had been cared for at a rehabilitation ward following their discharge from ICU, felt less of a need for follow-up session, but appreciated being able to return to the ICU. The findings support the importance of the follow-up session, and a return visit to the ICU, and the significance of processing things after one's illness.

\section{Implications}

The patients experienced the follow-up session as a valuable tool in processing things and moving on from their experiences of being a patient in an ICU. Those who had been cared for at a rehabilitation clinic following their discharge from ICU stated that they felt less of a need for follow-up, but appreciated being able to return to the ICU. The results support the importance of the follow-up and a return visit to the ICU, and the importance in processing things after one's illness. The study highlighted increasing collaboration between intensive care staff and staff in other units to provide support to this patient group in order to reduce their suffering post intensive care experience. 


\section{Acknowledgements}

We would like to express our warm and sincere gratitude to the nurses, Anne-Maja Person, Jessica Wernlid and Ingegerd Drotz, who were responsible for the follow up sessions; to the participants who shared their experiences; and to the Local Research and Development Council, Jönköping County, Sweden, for the grants. 


\section{References}

Backman CG, Orwelius L, Sjoberg F, Fredrikson M, Walther SM. Long-term effect of the ICU-diary concept on quality of life after critical illness. Acta Anaesthesiol Scand. 2010;54:736-743.

Backman CG, Walther SM. Use of a personal diary written on the ICU during critical illness. Intensive Care Med. 2001;27:426-429.

Barnett L. A neglected client group. Therapy today. 2006;4:19-21.

Chaboyer W, Grace J. Following the path of ICU survivors: a quality-improvement activity. Nurs Crit Care. 2003;8:149-155.

Cutler L, Brightmore K, Colqhoun V, Dunstan J, Gay M. Developing and evaluating critical care follow-up. Nurs Crit Care. 2003;8:116-125.

Downe-Wamboldt, B. Content analysis: method, applications, and issues. Health Care for Women International, 1992;13:313-321.

Egerod I, Christensen D. Analysis of patient diaries in Danish ICUs: a narrative approach. Intensive Crit Care Nurs. 2009;25:268-277.

Egerod I, Risom SS, Thomsen T, Storli SL, Eskerud RS, Holme AN, et al. ICU-recovery in Scandinavia: a comparative study of intensive care follow-up in Denmark, Norway and Sweden. Intensive Crit Care Nurs. 2013;29:103-111.

Engström Å, Andersson S, Söderberg S. Re-visiting the ICU Experiences of follow-up visits to an ICU after discharge: a qualitative study. Intensive Crit Care Nurs. 2008;24:233-241.

Forsberg A, Lindgren E, Engström Å. Being transferred from an intensive care unit to a ward: Searching for the known in the unknown. Int J Nurs Pract. 2011;17:110-116.

Frank C, Asp M, Fridlund B, Baigi A. Questionnaire for patient participation in emergency departments: Development and psychometric testing. J Adv Nurs. 2011;67:643-651. 
Graneheim UH, Lundman B. Qualitative content analysis in nursing research: concepts, procedures and measures to achieve trustworthiness. Nurse Educ Today. 2004;24:105-112. Human D, Fluss SS. The world medical association's declaration of Helsinki: Historical and Contemporary Perspectives. The World Medical Association Available: http://wwwmanet 2002.

Jones C, Backman C, Capuzzo M, Egerod I, Flaatten H, Granja C, et al. Intensive care diaries reduce new onset post traumatic stress disorder following critical illness: a randomised, controlled trial. Critical care. 2010;14:R168.

Jones C, Lyons C. Researching the experience of being critically ill: some methodological difficulties. Intensive Crit Care Nurs. 2003;19:365-369.

Jones C, Skirrow P, Griffiths R, Humphris G, Ingleby S, Eddleston J, Waldmann C, Gager M. Rehabilitation after critical illness: A randomized, controlled trial. Crit Care Med. 2003;31:2456-2461.

Knowles RE, Tarrier N. Evaluation of the effect of prospective patient diaries on emotional well-being in intensive care unit survivors: a randomized controlled trial. Crit Care Med. 2009;37:184-191.

Krippendorff K. Content Analysis: An Introduction to its Methodology, 2nd edn. Sage, Thousand Oaks, CA; 2004.

Lin F, Chaboyer W, Wallis M. A literature review of organisational, individual and teamwork factors contributing to the ICU discharge process. Aust Crit Care. 2009;22:29-43. Lincoln YS, Guba EG. Naturalistic inquiry. Newbury Park, CA: Sage; 1985. Löf L, Berggren L, Ahlström G. Severely ill ICU patients recall of factual events and unreal experiences of hospital admission and ICU stay--3 and 12 months after discharge. Intensive Crit Care Nurs. 2006;22:154-166. 
Nåden D, Eriksson K. Encounter: a fundamental category of nursing as an art. Int J Human Caring. 2002;6:34-40.

Pattison NA, Dolan S, Townsend P, Townsend R. After critical care: a study to explore patients' experiences of a follow-up service. J Clin Nurs. 2007;16:2122-2131.

Paul F, Hendry C, Cabrelli L. Meeting patient and relatives' information needs upon transfer from an intensive care unit: the development and evaluation of an information booklet. J Clin Nurs. 2004;13:396-405.

Polit DF, Beck CT. Nursing research : generating and assessing evidence for nursing practice. Philadelphia: Wolters Kluwer Health/Lippincott Williams \& Wilkins; 2012.

Prinjha S, Field K, Rowan K. What patients think about ICU follow-up services: a qualitative study. Crit Care. 2009;13:R46.

Rattray J, Crocker C, Jones M, Connaghan J. Patients' perceptions of and emotional outcome after intensive care: results from a multicentre study. Nurs Crit Care. 2010;15:86-93.

Rehnsfelt A, Eriksson K. The progression of suffering implies alleviated suffering. Scand J Caring Sciences 2004;18:264-272

Ringdal M, Johansson L, Lundberg D, Bergbom I. Delusional memories from the intensive care unit—Experienced by patients with physical trauma. Intensive Crit Care Nurs. 2006;22:346-354.

Roberts B, Rickard C, Rajbhandari D, Reynolds P. Patients' dreams in ICU: Recall at two years post discharge and comparison to delirium status during ICU admission: A multicentre cohort study. Intensive Crit Care Nurs. 2006;22:264-273.

Salisbury LG, Merriweather JL, Walsh TS. Rehabilitation after critical illness: could a wardbased generic rehabilitation assistant promote recovery? Nurs Crit Care. 2010;15:57-65. Samuelson KA. Unpleasant and pleasant memories of intensive care in adult mechanically ventilated patients--findings from 250 interviews. Intensive Crit Care Nurs. 2011;27:76-84. 
Samuelson KA, Corrigan I. A nurse-led intensive care after-care programme - development, experiences and preliminary evaluation. Nurs Crit Care. 2009;14:254-263.

Sandelowski, M. Focus on qualitative methods. Sample size in qualitative research. Research in Nursing and Health. 1995;18:479-482.

SIR. Svenska intensivvårdsregistret http://www.icuregswe.org/Documents/Guidelines/postIVA_uppföljning_21013.pdf Storli SL, Lind R. The meaning of follow-up in intensive care: patients' perspective. Scand J Caring Sci. 2009;23:45-56.

Storli SL, Lindseth A, Asplund K. A journey in quest of meaning: a hermeneuticphenomenological study on living with memories from intensive care. Nurs Crit Care. 2008;13:86-96.

Strahan E, McCormick J, Uprichard E, Nixon S, Lavery G. Immediate follow-up after ICU discharge: establishment of a service and initial experiences. Nurs Crit Care. 2003;8:49-55. Williams SL. Recovering from the psychological impact of intensive care: how constructing a story helps. Nurs Crit Care. 2009;14:281-288.

VRFS. Vetting the ethics of research involving humans Ethical Review Act Available: http://www.epnse/en2012. 